Review article

\title{
Ranking of crop plants according to their potential to uptake and accumulate contaminants of emerging concern
}

\author{
Anastasis Christou ${ }^{\mathrm{a}, *}$, George Papadavid ${ }^{\mathrm{a}}$, Panagiotis Dalias ${ }^{\mathrm{a}}$, Vasileios Fotopoulos ${ }^{\mathrm{b}}$, \\ Costas Michael $^{\mathrm{c}}$, Josep Maria Bayona ${ }^{\mathrm{d}}$, Benjamin Piña ${ }^{\mathrm{d}}$, Despo Fatta-Kassinos ${ }^{\mathrm{c}, \mathrm{e}, * *}$ \\ ${ }^{a}$ Agricultural Research Institute, Ministry of Agriculture, Rural Development and Natural Recourses, P.O. Box 22016, 1516 Nicosia, Cyprus \\ ${ }^{\mathrm{b}}$ Department of Agricultural Sciences, Biotechnology and Food Science, Cyprus University of Technology, 3603 Lemesos, Cyprus \\ ${ }^{c}$ NIREAS-International Water Research Center, University of Cyprus, P.O. Box 20537, 1678 Nicosia, Cyprus \\ ${ }^{\mathrm{d}}$ IDAEA-CSIC, Environmental Chemistry Department, E-08034, Barcelona, Spain \\ ${ }^{\mathrm{e}}$ Department of Civil and Environmental Engineering, University of Cyprus, P.O. Box 20537, 1678 Nicosia, Cyprus
}

A R T I C L E I N F O

\section{Keywords:}

Bioaccumulation

Crop evapotranspiration

Leafy vegetable

Plant physiology

Treated wastewater

\begin{abstract}
A B S T R A C T
The reuse of treated wastewater (TWW) for irrigation and the use of biosolids and manures as soil amendment constitute significant pathways for the introduction of the contaminants of emerging concern (CECs) to the agricultural environment. Consequently, CECs are routinely detected in TWW-irrigated agricultural soils and runoff from such sites, in biosolids- and manure-amended soils, and in surface and groundwater systems and sediments receiving TWW. Crop plants grown in such contaminated agricultural environments have been found to uptake and accumulate CECs in their tissues, constituting possible vectors of introducing CECs into the food chain; an issue that is presently considered of high priority, thus needing intensive investigation. This review paper aims at highlighting the responsible mechanisms for the uptake of CECs by plants and the ability of each crop plant species to uptake and accumulate CECs in its edible tissues, thus providing tools for mitigating the introduction of these contaminants into the food chain. Both biotic (e.g. plants' genotype and physiological state, soil fauna) and abiotic factors (e.g. soil pore water chemistry, physico-chemical properties of CECs, environmental perturbations) have been proven to influence the ability of crop plants to uptake and accumulate CECs. According to authors' estimates, based on the thorough elaboration of knowledge produced by existing relevant studies, the ability of crop plants to uptake and accumulate CECs decrease in the order of leafy vegetables $>$ root vegetables > cereals and fodder crops > fruit vegetables; though, the uptake of CECs by important crop plants, such as fruit trees, is not yet evaluated. Overall, further studies must be performed to estimate the potential of crop plants to uptake and accumulate CECs in their edible tissues, and to characterize the risk for human health represented by their presence in human and livestock food products.
\end{abstract}

\section{Introduction}

Climate change and the global warming effects are widely recognized during the recent decades, and therefore water availability and water management issues are of special significance in all arid and semi-arid regions worldwide (March et al., 2012). Agriculture is likely to encounter the most serious threats due to water scarcity, as it is the major consumer of water. At the same time, demographic shifts, economic development and lifestyle changes are expected to intensify the competition between agricultural and other uses of water, such as municipal and industrial (Iglesias and Garrote, 2015). Water imbalances in the agricultural sector in most arid and semi-arid countries are expected to be further intensified, as limited and unequally distributed rainfall follows declining trend, whereas mean temperature is steadily increasing (Milano et al., 2012), having as a result the increase of crop evapotranspiration (ETc) and net irrigation requirements (NIR)

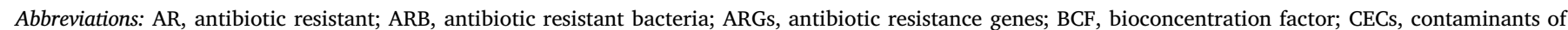
emerging concern; DOM, dissolved organic matter; ETc, crop evapotranspiration; $f_{n}$, fraction of neutral molecules; $K_{\text {ow }}$, octanol-water partition coefficient; NIR, net irrigation requirements; PhACs, pharmaceutically active compounds; PCPs, personal care products; RCF, root concentration factor; TWW, treated wastewater; SCF, shoot concentration factor; SOM, soil organic matter

* Corresponding author.

** Corresponding author at: Department of Civil and Environmental Engineering, University of Cyprus, P.O. Box 20537, 1678 Nicosia, Cyprus.

E-mail addresses: anastasis.christou@ari.gov.cy (A. Christou), dfatta@ucy.ac.cy (D. Fatta-Kassinos). 
(Trapp, 2015). A great number of integrated water resource management schemes are already being implemented, or are under consideration, with particular focus being given to the exploitation of existing water resources and the utilization of non-conventional water resources, such as treated wastewater (TWW) (Milano et al., 2012). As a result, TWW reuse, mainly for irrigation purposes, is already an established practice around the world (Bixio et al., 2006; Zhang and Shen, 2017). Although TWW reuse for irrigation has gained an acceptance as an economic alternative that could substitute nutrient needs and water requirement of crop plants, and major advances have been made with respect to producing safe treated effluents for reuse (e.g. successful removal of nutrients, metals, chemical oxygen demand down to low levels), TWW still may contain undesirable chemicals, primarily organic constituents, and pathogens that may represent significant environmental and health risks (Fatta-Kassinos et al., 2011). Consequently, several important questions concerning the presence of organic microcontaminants in TWW and their subsequent release into the environment through TWW irrigation are still unanswered and barriers exist regarding the safe/sustainable reuse practices. Given our relatively low knowledge of their potential toxicity, many of these microcontaminants, including pharmaceuticals, antibiotics, chemicals from personal care products, endocrine disrupting compounds, plasticizers, flame retardants, surfactants, illicit drugs, transformation products, pesticides, etc., are referred to as contaminants of emerging concern (CECs). Available/applied treatment technologies fail to completely remove CECs while no consolidated information exists concerning the fate of CECs within the biomass of activated sludge, in the TWW and in the agricultural environment (i.e. soil, ground/surface waters, plants/ crops), in the framework of reuse applications (i.e. irrigation, groundwater replenishment, storage in surface waters for subsequent reuse) (Fatta-Kassinos et al., 2011).

CECs, and most specifically pharmaceutically active compounds (PhACs) and personal care products (PCPs) are also introduced into the environment via various human activities, including direct disposal of unused or expired medication, release from pharmaceutical manufacturing plants and hospitals, and veterinary drug use (Grossberger et al., 2014). Moreover, most PhACs are poorly absorbed and not completely metabolized in human and animal bodies and thus a great proportion of the administrated dosage (ranging from 10 up to $90 \%$ ) is excreted via urine and faeces within hours after their application, either as parent compounds or as metabolites (Liu et al., 2010; Zhang et al., 2014). As a result, PhACs may directly enter the environment through the application of animal manures to soil and the excretions by grazing livestock (Pan and Chu, 2016). Besides the reuse of TWW for irrigation, the use of biosolids as soil amendment constitutes an additional significant pathway for the introduction of CECs in the agricultural environment (Borgman and Chefetz, 2013). Therefore, CECs are detected in TWW-irrigated agricultural soils and in the runoff from such sites, in biosolids- and manure-amended soils, and in surface and groundwater systems and sediments receiving TWW (Kolpin et al., 2002; Pedersen et al., 2003; Kinney et al., 2006; Fatta-Kassinos et al., 2011; Gottschall et al., 2012; Luo et al., 2014; Meffe and de Bustamante, 2014).

The contamination of the environment, and possibly the food chain with CECs is presently considered as a serious public health problem (Rand-Weaver et al., 2013; Malchi et al., 2014; Pan et al., 2014; Prosser and Sibley, 2015). However, since solid data regarding the actual uptake of these contaminants by crop plants under actual farming conditions are largely missing, knowledge gaps do still exist with regard to the potential CECs-mediated effects on public health due to the consumption of CECs-contaminated food. A further level of concern is the one represented by antibiotics, as they may induce the generation and the propagation of antibiotic-resistant bacteria in water treatment plant facilities, in exposed soils, in the receiving crops, and, ultimately, in the consumer's gut, although the real extend of this potential risk has not been adequately evaluated yet (Ashbolt et al., 2013; Manaia et al., 2018; Piña et al., 2018).
The uptake and bioaccumulation of CECs in the edible parts of food crops and fodders and their subsequent entry into the food chain have gained prominence over the last several years. Numerous studies, mainly conducted under controlled conditions, highlighted that plants exposed to known concentrations of individual or cocktails of CECs through irrigation with TWW or CECs-spiked irrigation water or by grown in manure- and biosolids-amended soils, uptake and accumulate these contaminants in their tissues, in the range of low $\mu \mathrm{g} \mathrm{kg}^{-1}$ to low $\mathrm{mg} \mathrm{kg}^{-1}$ (Tanoue et al., 2012; Wu et al., 2012; Dodgen et al., 2015; Christou et al., 2016). Such studies were proven to be useful in elucidating the mechanisms of CECs uptake by plants, which was found to be simply driven by the transpiration derived mass flow and largely depended among others on the physico-chemical properties of the compounds, especially their hydrophobicity, chemical structure and charge. Controlled experiments though, even if conducted at environmentally relevant CECs concentrations, are unable to manifest the complexity of an actual agricultural environment (Malchi et al., 2014). Field studies, conducted in agricultural fields by applying TWW for irrigation or biosolids and manures as soil amendment provide additional information with regard to CECs uptake by crop plants, while also set an actual frame for assessing the potential health impacts derived from the consumption of CECs-contaminated agricultural produce (Wu et al., 2014; Franklin et al., 2016; Christou et al., 2017c). It is however unrealistic to study the potential for CECs uptake for all the wide range of cultivated crop species. This review paper aims at highlighting the main parameters that affect the CECs uptake process by crop plants, including environmental factors and plant physiology and genotype, and providing a ranking of crop species according to their ability to uptake and accumulate CECs, by utilizing the up to date available knowledge.

\section{Environmental factors that affect the uptake of CECs by plants}

Several categories of CECs have been proven to be taken up through roots and translocated to the aerial parts of crop plants grown not only under hydroponic or greenhouse controlled conditions, but also in manure- and biosolids-amended and TWW-irrigated soils under real agricultural systems (Tanoue et al., 2012; Goldstein et al., 2014; Wu et al., 2015; Miller et al., 2016; Christou et al., 2017c). However, our understanding of the CECs uptake mechanism by crop plants remains rather limited, despite the relatively large number of studies undertaken in order to investigate the root uptake of CECs (Miller et al., 2016). It has been previously shown that the uptake of CECs by crop plants is largely dependent on their bioavailability/bioaccessibility in soil pore water near the rhizosphere, driven by their physico-chemical properties and on the properties of the soil environment (Goldstein et al., 2014; Christou et al., 2017a). In addition, their sorption onto soil constituents and their transformation by soil organisms may reduce their bioavailability. Once taken up, the transport of CECs within the plant vascular translocation system (xylem and phloem) largely depends on their physico-chemical properties (i.e. lipophilicity and electrical charge), as well as on the plant's physiology and transpiration rate (Goldstein et al., 2014; Dodgen et al., 2015) and on the different environmental conditions (i.e. drought stress) (Zhang et al., 2016). CECs have been proven to enter the root through the epidermis of growing root tips and subsequently pass through the cortex and the endodermis to reach the vascular tissues, where they can then be transported via the xylem or phloem to aboveground tissues. The presence of the Casparian strip in the endodermis of roots, which acts as a hydrophobic barrier between the apoplast and the vascular tissue, suggests that CECs must follow the symplastic route, which is constituted of selective binding sites and channels, at least for once (Kong et al., 2007; Tanoue et al., 2012; Malchi et al., 2014). As a result, the lipophilicity and speciation of CECs strongly affects their root uptake by and subsequent translocation within the plants.

A significant proportion of CECs are ionizable substances, thus CECs can be neutral, cationic, anionic or zwitterionic under different $\mathrm{pH}$ 
conditions (Boxall et al., 2012). Nonionic CECs are able to cross cell membranes easily and thus have higher potential to be taken up by the roots (Trapp, 2000). Once in the root, these compounds tend to move from xylem to phloem and vice versa, and thus are being transported predominantly in the direction of the transpiration stream and accumulated mostly in transpiring organs (i.e. leaves) (Trapp, 2004; Goldstein et al., 2014). On the other hand, ionizable CECs may undergo dissociation in soil-pore water depending on its $\mathrm{pH}$ value, which along with their hydrophobicity greatly influence their uptake by and translocation within the plants. Thus, the electrical attraction or repulsion of ionizable CECs to the negatively charged root surface, and ion trap effects may affect their accumulation in roots. Usually, ionic CECs cross membranes at a slower rate than non-ionic CECs (Trapp, 2000) and therefore molecular dissociation may lead to reduced accumulation in roots and lower uptake compared to neutral CECs (Goldstein et al., 2014). The ionic trapped CECs are expected to be translocated preferentially in the phloem rather than in the xylem, and as opposed to the nonionic CECs, be accumulated in the fruit than in the leaves (Goldstein et al., 2014). Miller et al. (2016) suggest that acidic CECs with $\mathrm{pK}_{\mathrm{a}}<7$ and $\log \mathrm{K}_{\mathrm{ow}}<3$ tend to remain in the phloem due to iontrapping mechanisms and can move to fruits, whereas concerning the basic CECs with $\mathrm{pK}_{\mathrm{a}}>7$, those with $\log \mathrm{K}_{\mathrm{ow}}<0$ tend to be ambimobile (mobile in both the xylem and the phloem) and those with $0<\log$ $\mathrm{K}_{\mathrm{ow}}<4$ tend to move in xylem.

The uptake of CECs by crop plants grown in real agricultural systems, where a cocktail of CECs is often present and the complexity of soil-plant-environment interactions are also taken into account, has not been extensively studied. Several studies followed experimental setups where real TWW was applied for the irrigation of crop plants in the field, or where biosolids or manure was applied as soil amendment in agricultural fields, practices that have become typical for commercial agriculture farming (Calderón-Preciado et al., 2011a, 2011b, 2013; Shenker et al., 2011; Goldstein et al., 2014; Malchi et al., 2014; Marsoni et al., 2014; Pan et al., 2014; Prosser et al., 2014; Wu et al., 2014; Hurtado et al., 2016; Riemenschneider et al., 2016; Christou et al., 2017c; Picó et al., 2019), allowing for the assessment of the actual potential uptake of CECs by crops (Malchi et al., 2014; Prosser and Sibley, 2015). These studies have enabled researchers to better understand the effects of the agricultural environment on the uptake and accumulation of CECs in the edible parts of crop plants. Results showed that the properties of the agricultural soil and the soil environment in general, as well as the environment of the agro-ecosystems, greatly shape and determine the uptake of CECs by crop plants.

\subsection{Soil environment}

Accumulating evidence show that crops growing in agricultural soils with low levels of organic matter, or sandy soils, or soils that have low proportion of clay compared to silt and sand may have higher potential to uptake CECs compared to clay soils or soils rich in organic matter, given that the appropriate irrigation regime is applied (Goldstein et al., 2014; Malchi et al., 2014). Malchi et al. (2014) studied the uptake of PhACs by carrots and sweet potatoes grown in lysimeters filled with three different soil types (sandy clay, loamy sand and sandy loam) and found that PhACs were in higher concentrations in the roots and leaves of those plants grown in sandy soils compared to those grown in loamy soils. Similarly, Goldstein et al. (2014) reported that nonionic PhACs were taken up and accumulated at higher levels in the leaves and fruits of tomato and cucumber plants grown in soils of lower organic matter and clay content. Moreover, Zhang et al. (2016) studied the uptake of three antibiotics (sulfamethoxazole, lincomycin, and oxytetracycline) by lettuce plants grown in three soils with variability in texture (loam, sandy loam, and sand) and found that only sulfamethoxazole was detected in lettuce leafs, showing a positive correlation between pollutant uptake ratios and the sand content in soil. These studies, highlight the role of soil texture and soil environment on the potential of plants to uptake and accumulate CECs, as these variables greatly determine the fate of CECs in the soil, and thus, their bioavailability and bioaccessibility for microbial degradation and uptake by plants. It is now well documented that once introduced into soil, CECs are subjected to sorption/desorption and transformation processes (both biotic and abiotic), which influence their concentration being available for biodegradation, transport into soil (runoff and leaching) and uptake by plants, ultimately specifying the potential of accumulation of CECs in soil and plants (Dalkmann et al., 2012; Grossberger et al., 2014). The chemical properties of CECs that significantly impact and shape their environmental fate are polarity, hydrophobicity and water solubility. Polar and ionizable CECs engage in interactions with the soil organic matter (SOM), the mineral surfaces and the dissolved organic matter (DOM). These interactions include hydrophobic partitioning, electron donoracceptor interactions (e.g., hydrogen bonding), cation-anion exchange, protonation, water binding, cation binding and surface complexation (Thiele-Bruhn et al., 2004; Vasudevan et al., 2009). Therefore, the physico-chemical properties of CECs, the chemistry of soil pore-water (i.e. $\mathrm{pH}$, mineral concentration, cation exchange capacity, DOM), and the soil structure (i.e. clay composition) and SOM content are critical factors controlling the retention of CECs in soil, and therefore their bioavailability and potential for uptake by crop plants (Vasudevan et al., 2009; Wu et al., 2013; Miller et al., 2016; Park and Huwe, 2016).

Growing on well aerated soils, contrary to on partially or non-aerated ones, such as compacted and waterlogged soils, may facilitate the uptake of CECs by plants. Aeration of soil may facilitate the respiration and functionality of roots in the rhizosphere, the uptake of water and nutrients, and plant growth (Juraske et al., 2009), and therefore the uptake of CECs. On the other hand, CECs in their ionic form, which is predominant in soils with $\mathrm{pH}$ higher than the $\mathrm{pK}_{\mathrm{a}}$ of the compound, have lower potential to be taken up by plants, due to repulsion forces exerted by the negatively charged root epidermis (Goldstein et al., 2014; Miller et al., 2016). In contrary, soils with acidic pH values (e.g. soil $\mathrm{pH}<$ compound $\mathrm{pK}_{\mathrm{a}}$ ) may result in the presence of contaminants in their neutral form (high fraction of neutral molecules $\left(f_{n}\right)$ values), thus facilitating their uptake (Fig. 1). To this effect, the antibiotic trimethoprim was reported to be predominantly present in its neutral form in alkaline soils $(\mathrm{pH}>8)$, thus facilitating its uptake by tomato plants (Christou et al., 2017c).

\subsection{Climatic conditions}

Other environmental factors, like the ambient temperature, the wind speed and the air humidity, may affect the uptake of CECs by crops plants by shaping their evapotranspiration rate, and therefore their water and nutrient uptake (Allen et al., 1998). Plants grown in high wind and low air humidity conditions show increased water and nutrient uptake, and a subsequent higher potential for CECs uptake. Overall, it can be assumed that crop plants grown in hot and dry agricultural sites (e.g. Mediterranean region) may show increased rates of CECs uptake compared to plants grown in cold or humid regions. Drought stress, implying dry climatic conditions and limited water availability, has recently been reported to affect the uptake of CECs by plants. Zhang et al. (2016) showed that increased drought stress resulted in increased uptake of lincomycin and decreased uptake of oxytetracycline and sulfamethoxazole in TWW-irrigated lettuce plants. Dodgen et al. (2015) showed that the transpiration rate of plants may play a significant role in the uptake and translocation of CECs, which may have a pronounced effect in arid and hot climates where irrigation with TWW is common. Therefore, the evapotranspiration rate of crop plants (Table 1), determined by climatic and plant specific values (crop coefficient; Kc) may be a good indicator for the ability of crop plants to uptake and accumulate CECs > in their tissues. Worth noting, Table 1 shows the mean values of both ETc and NIR, as well as the irrigation period of the most important crops growing in medium-textured soil in the Mediterranean region. Plants with high evapotranspiration rate and 
Environmental factors affecting the potential for CECs' uptake by plants

\begin{tabular}{|c|c|c|c|}
\hline \multirow{6}{*}{$\begin{array}{c}\text { factors affecting } \\
\text { evapotranspirati } \\
\text { on }\end{array}$} & + & & - \\
\hline & high temperature & $\leftrightarrow$ & low temperature \\
\hline & high wind speed & $\leftrightarrow$ & calm wind - low wind speed \\
\hline & low air humudity & $\leftrightarrow$ & high air humitidy \\
\hline & hot and dry agricultural areas & $\leftrightarrow$ & cold continental agricultural areas \\
\hline & adequate soil moisture & $\leftrightarrow$ & drought \\
\hline
\end{tabular}

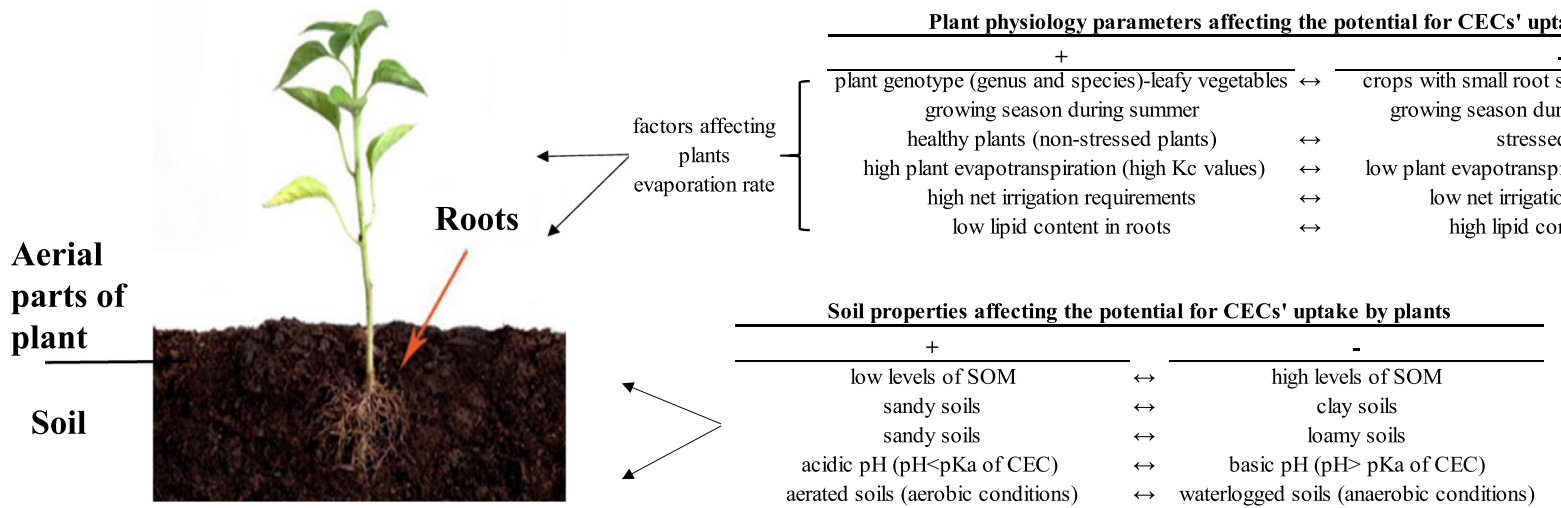

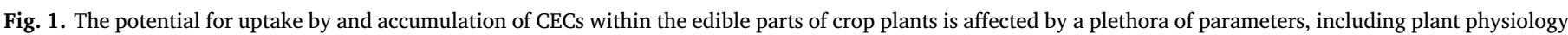

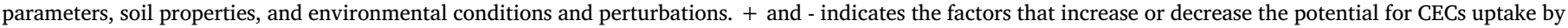
crop plants, respectively.

NIR values are expected to show higher potential for CECs uptake when grown in hot and dry conditions (thus irrigated in short intervals). Such crop plants are bananas, citrus, fruit trees, walnut (fruit trees), cucumber, eggplant, green beans, melons, pepper, tomatoes (vegetable plants), peanuts and alfalfa (arable crops). Furthermore, seasonal crops that are growing during the summer period (i.e. vegetables) and crops grown in greenhouses irrigated with TWW, as well as perennial crops for which TWW irrigation is practiced all year round for a prolonged period (i.e. fruit trees) may be categorized as plants with high potential for CECs uptake. On the other hand, crops grown during the autumn and winter period, where irrigation with TWW is irregularly practiced because of the precipitation events, as well as succulent plants (i.e. agave, Aloe vera), may well be categorized as crop plants with the lowest potential for CECs uptake. Importantly, leafy vegetables (i.e. lettuce, spinach, cabbage, broccoli, celery, etc.), often cultivated intensively all year round (thus irrigated), may accumulate greater concentrations of CECs in their edible tissues.

\section{Plant physiology factors affecting the uptake of CECs}

The physiology of plants greatly determines their potential to uptake and accumulate CECs. Plants exposed to environmental perturbations respond by inducing various adaptive mechanisms, such as the antioxidant defense mechanism, the closure of stomata for controlling respiration, the osmoregulation by accumulating organic osmolytes, as well as ion sequestration and exclusion, hormone regulation, and metabolic, transcriptional and post-translational modifications, etc. (Ahuja et al., 2010). Therefore, plants that are exposed to adverse environmental conditions may exert different patterns of CECs uptake compared to plants grown under optimum environmental conditions. It can be therefore assumed that non-stressed plants have higher potential for CECs uptake compared to stressed ones, as growth and development rates and consequently, water and nutrient uptake and photosynthetic efficiency, decrease significantly in plants grown under stress conditions (Hepworth et al., 2015).

Moreover, other physiological features of crop plants have been shown to affect their uptake potential. Goldstein et al. (2014) reported that the concentration of CECs in cucumber and tomato leaves of plants grown in three different soils in pots were of similar order, whereas their concentration in the tomato fruit were much lower compared to that in the cucumber fruit. This was attributed to differences in fruit physiology and specifically to the fact that cucumber fruits exert physiological responses and functions similar to those of leaves, as the chlorophyll content of the exocarp and the efficiency of PSII of fruits is similar to that of leaves (cucumber fruits transpire water, while also facilitate the direct fixation of atmospheric $\mathrm{CO}_{2}$ and recapture of respired $\mathrm{CO}_{2}$, contributing to fruit growth) (Fantke et al., 2011).

The lipid content of roots has also been found to affect the ability of different plant species to uptake CECs. Eggen et al. (2011) reported that four carrot cultivars grown in soil spiked with metformin, in pots in greenhouse, displayed significantly different uptake patterns, with the bioconcentration factor (BCF) for leaves in low-lipid-content carrot roots being significantly higher (in the order of 2- to 4-fold) compared to that in high-lipid-content carrot roots. Gao and Zhu (2004) reported opposite results, as the root concentration factors for both phenanthrene and pyrene in 12 different plant species (amaranth, flowering Chinese cabbage, radish, water spinach, green soybean, kidney bean, pakchoi, broccoli, sinage, capsicum, eggplant and ryegrass) grown in soil spiked with varying concentrations of these CECs displayed significant positive correlation $\left(\mathrm{R}^{2} \geq 0.8\right)$ with plant root lipid content. Similar results were found by Huang et al. (2009), as the root concentration of decabromodiphenyl ether (BDE-209) in ryegrass, alfalfa, pumpkin, squash, maize and radish plants grown in spiked soil $\left(5000 \mu \mathrm{g} \mathrm{kg}^{-1}\right)$ was also found positively related to plant root lipid content.

\section{Plant species and genotype}

Plant species within the same genus have been reported to have different patterns of CECs uptake. For example, different species of the Brassica genus have been shown to exert distinct uptake patterns for PhACs carbamazepine, salbutamol, sulfamethoxazole, and trimethoprim. More precisely, cabbage (Brassica rapa var. pekinensis) and Wisconsin Fast Plants (Brassica rapa) grown hydroponically in nutrient solution spiked with these four PhACs displayed different concentrations in roots, leaves, stems or seedpods (Herklotz et al., 2010). Moreover, Eggen et al. (2011) showed that varieties of the same species may also exert different patterns of CECs uptake, as the carrot varieties Napoli, Amagar, Rothild and Nutri Red displayed completely distinct uptake patters for the PhACs metformin, ciprofloxacin and narasin. These 
Table 1

Average annual crop evapotranspiration (ETc) and net irrigation requirements (NIR) values, as well as the irrigation period of the main cultivated crop species in the Mediterranean region, during the period 1990-2014, as estimated by Christou et al. (2017b).

\begin{tabular}{|c|c|c|c|}
\hline Crops & $\begin{array}{l}\text { ETc } \\
\text { Total ETc ( } \mathrm{m}^{3} \text { water/ ha/ year) }\end{array}$ & $\begin{array}{l}\text { NIR } \\
\text { Total NIR ( } \mathrm{m}^{3} \text { water/ ha/ year) }\end{array}$ & Irrigation period $^{\mathrm{a}}$ \\
\hline \multicolumn{4}{|l|}{ Tree crops } \\
\hline Almonds & 3445 & 3364 & Jun-Sep \\
\hline Bananas & 12,184 & 11,340 & Mar-Nov \\
\hline Citrus \& Avocado & 8237 & 7615 & Mar-Nov \\
\hline Fruit trees (Lowlands/plains) & 7973 & 7836 & Mar-Oct \\
\hline Fruit trees (Mountains) & 6641 & 6504 & May-Oct \\
\hline Pistachio & 3443 & 3362 & Jun-Sep \\
\hline Table grapes & 3023 & 2845 & Apr-Jun \\
\hline Table olives & 4186 & 3867 & Apr-Oct \\
\hline Walnut (Pecan) & 9676 & 9358 & Apr-Oct \\
\hline \multicolumn{4}{|l|}{ Vegetables } \\
\hline Artichokes & 4390 & 3715 & Mar-Apr,Aug-Nov \\
\hline Cabbage & 2972 & 2559 & Jul-Nov \\
\hline Carrots & 4180 & 2998 & Mar-May,Nov-Dec \\
\hline Celery & 4216 & 3576 & Sep-Nov, Mar \\
\hline Cucumber (greenhouse) & 5713 & 5713 & Oct-May \\
\hline Cucumber & 4649 & 4456 & Apr-Jul \\
\hline Eggplants & 5766 & 5448 & Apr-Oct \\
\hline Green beans (greenhouse) & 4414 & 4414 & Oct-May \\
\hline Green beans & 5992 & 5696 & Mar-Jul \\
\hline Lettuce & 3265 & 2268 & Oct-Dec \\
\hline Marrows & 4976 & 4772 & Apr-Aug \\
\hline Melons & 5069 & 4865 & Apr-Aug \\
\hline Okra & 6616 & 6289 & Mar-Aug \\
\hline Peas & 1926 & 1594 & Mar-May \\
\hline Pepper & 5399 & 5173 & Apr-Sep \\
\hline Potatoes (spring) & 2994 & 2641 & Mar-May \\
\hline Potatoes (mid season) & 1360 & 759 & Oct-Feb \\
\hline Potatoes (late season) & 4760 & 4300 & Jul-Nov \\
\hline Radish & 4051 & 3410 & Sep-Nov, Mar \\
\hline Spinach & 3535 & 3101 & Sep-Nov \\
\hline Tomatoes (greenhouse) & 7342 & 7342 & Oct-Jul \\
\hline Tomatoes & 6363 & 6136 & Apr-Sep \\
\hline Watermelons & 4976 & 4772 & Apr-Aug \\
\hline \multicolumn{4}{|l|}{ Arable crops } \\
\hline Haricot beans & 4440 & 4300 & Jul-Oct \\
\hline Peanuts (Monkey nuts) & 5153 & 4927 & Apr-Sep \\
\hline
\end{tabular}

a Irrigation period in the Mediterranean Basin.

differences are relevant, as cultivated crop species may be available to farmers in dozens or even more varieties, which are adapted to different climatic conditions, or having different productivity and fruit quality characteristics (taste, resistant to pest and diseases, resistance to salinity or other stress factors, etc.). Moreover, a number of different cultivars may be even grown in a specific region due to farmers or consumers' preferences, highlighting the difficulties and challenges in defining the potential to uptake and accumulate CECs in a single cultivated species (e.g. carrot, tomato, etc.).

\section{Studies reporting CECs uptake by crop plants in real or simulated agricultural environments receiving TWW for irrigation or amended with manure or biosolids}

Only few studies (out of hundreds) reporting the uptake and accumulation of CECs by crop plants either irrigated with TWW or grown in biosolids- or manure-amended soil were performed in real field or simulated conditions. Moreover, even fewer studies have reported the concentration of studied CECs in both the growing medium (i.e. soil) and the edible tissues of crop plant species, thus allowing for the estimation of the BCF and therefore the real ability of crop plants to uptake and accumulated CECs in their tissues. Authors herein report these studies, aiming at elucidating the real potential of crop plants to uptake and accumulate CECs in their tissues, by calculating the BCFs in each study. For example, Pan et al. (2014) evaluated the accumulation of antibiotics (tetracycline, sulfamethazine, norfloxacin, erythromycin, chloramphenicol) in vegetable and cereal crops (Chinese white cabbage, water spinach, Chinese radish, corn, maize) irrigated with sewage for a prolonged period (20 years) in Southern China, and found that the concentration of antibiotics in the different edible parts of the various crops followed specific trends. Norfloxacin was consistently found at the highest concentrations $\left(4.6-23.6 \mu \mathrm{g} \mathrm{kg}^{-1} \mathrm{dry}\right.$ weight, d.w.) in crop tissues, followed by chloramphenicol $\left(2.6-22.4 \mu \mathrm{g} \mathrm{kg}^{-1} \mathrm{~d} . \mathrm{w}\right)$ and tetracycline $\left(4.0-10.1 \mu \mathrm{g} \mathrm{kg}^{-1}\right.$ d.w.), whereas sulfamethazine and erythromycin were not detected in most of the vegetable crops tested. Chloramphenicol displayed the higher BCF in leaf and shoots, with the highest BCF being reported in Chinese radish, followed by corn and rice, and Chinese white cabbage and water spinach, while tetracycline and norfloxacin displayed similar BCF in all studied crops.

The uptake of $16 \mathrm{PhACs}$ (acetaminophen, caffeine, meprobamate, atenolol, trimethoprim, carbamazepine, diazepam, gemfibrozil, primidone, sulfamethoxazole, dilantin, diclofenac, naproxen, ibuprofen, atorvastatin and fluoxetine) and three PCPs (N,N-diethyl-metatoluamide; DEET, triclosan, and triclocarban) by eight common vegetables (carrot, celery, lettuce, spinach, cabbage, cucumber, bell pepper, and tomato) grown in field and irrigated with fortified ( $250 \mathrm{ng} \mathrm{L}^{-1}$ of each CECs) and non-fortified tertiary treated wastewater, was evaluated by Wu et al. (2014). The analysis of the edible tissues of these plants showed that the studied CECs where detected in the $64 \%$ and $91 \%$ of the samples collected from the TWW and the fortified TWW treatments, respectively. Thus, it was shown that the concentration of the CECs in the irrigation water is a key factor in the uptake process. The edible samples from the 
two treatments contained the same CECs, including caffeine, meprobamate, primidone, DEET, carbamazepine, dilantin, naproxen, and triclosan. The total concentrations of CECs detected in edible tissues from the treated wastewater and fortified wastewater irrigation treatments were in the range of $0.01-3.87$ and $0.15-7.3 \mu \mathrm{g} \mathrm{kg}^{-1}$ (d.w.), respectively, while the annual exposure of CECs from the consumption of mature vegetables irrigated with the fortified wastewater was estimated to be only $3.69 \mu \mathrm{g}$ per capita. Importantly, leafy (celery, lettuce, cabbage) and root vegetables (carrot) displayed higher concentrations of the studied CECs in their edible tissues, compared to fruit vegetables (cucumber, bell pepper, tomato), with the sole exception of spinach.

The uptake of nonionic PhACs (carbamazepine, caffeine, and lamotrigine) and ionic pharmaceuticals (metoprolol, bezafibrate, clofibric acid, diclofenac, gemfibrozil, ibuprofen, ketoprofen, naproxen, sulfamethoxazole, and sildenafil) by TWW-irrigated root crops (carrots and sweet potatoes) grown in lysimeters was monitored, in a field study (Malchi et al., 2014). In both crops, the nonionic PhACs were detected at significantly higher concentrations than ionic PhACs in both the leafs and roots. The concentration for most of the studied PhACs (carbamazepine, lamotrigine, sildenafil, clofibric acid, bezafibrate, sulfapyridine) were higher in the carrots' than in the sweet potatoes' edible parts.

Goldstein et al. (2014) studied the uptake and translocation of several PhACs (carbamazepine, caffeine, lamotrigine, metoprolol, bezafibrate, clofibric acid, gemfibrozil, ibuprofen, ketoprofen, naproxen, sulfamethoxazole, sildenafil and sulfapyridine) in cucumber and tomato plants with the aim to elucidate the effects of the physico-chemical properties of PhACs, the soil type, and the irrigation-water quality on the uptake and translocation of PhACs by plants. Nonionic PhACs were taken up and accumulated at higher levels in plants grown in soils of lower organic matter and clay content. While the concentration of most PhACs in cucumber and tomato leaves were of similar order, their concentrations in the tomato fruit were much lower than in the cucumber fruit. Lamotrigine, carbamazepine and caffeine were found in higher concentrations in cucumber fruits, whereas, ibuprofen, clofibric acid, caffeine, sildenafil and carbamazepine were found in higher concentrations in tomato fruit, compared to that of the other studied pharmaceuticals.

Riemenschneider et al. (2016) studied the uptake of 28 CECs and carbamazepine metabolites in 10 different field-grown vegetable species (tomato, eggplant, zucchini, pepper, cabbage, lettuce, parsley, rucola, potato, and carrot) irrigated with water of the Zarqa River (consisting of TWW as the main component), in Jordan. Results revealed that a total of 18 CECs (including six carbamazepine metabolites) could be detected in all of the samples in concentrations ranging from 1.7 to $216 \mu \mathrm{g} \mathrm{kg}^{-1}$ (d.w.). Among the studied vegetables, the highest total concentrations of CECs in edible parts were found for lettuce $\left(347 \mu \mathrm{g} \mathrm{kg}^{-}\right.$ ${ }^{1}$ d.w.), followed by parsley (204 $\mu \mathrm{g} \mathrm{kg}^{-1}$ d.w.) and rucola (147 $\mu \mathrm{g} \mathrm{kg}^{-1}$ d.w.), all being leafy crops. Generally, the total concentration of the studied CECs decreased in the order of leafy $>$ root $>$ fruit-bearing vegetables. The total concentration in leafy vegetables was on average 3.7 times higher compared to that of the edible part of root and fruitbearing vegetables.

By conducting a field study, Christou et al. (2017c) explored the long-term (three years) effects of irrigation with two distinctly tertiary treated wastewater effluents containing diclofenac, sulfamethoxazole and trimethoprim on tomato plants and on the irrigated soil. The concentration of these PhACs was determined in fruits harvested at the end of the harvesting period (last harvest) for the first two years of the study, while at the third year of the study the concentration of PhACs were determined at fruits harvested at the beginning (first harvest), middle (fourth harvest) and the end of the harvesting period (seventh harvest) (seven to eight harvests took place in each year of the study). The pharmaceutical with the highest soil concentration throughout the studied period was sulfamethoxazole $\left(0.98 \mu \mathrm{g} \mathrm{kg}^{-1}\right.$ d.w. $)$, followed by trimethoprim $\left(0.62 \mu \mathrm{kg}^{-1}\right.$ d.w.) and diclofenac $\left(0.35 \mu \mathrm{kg}^{-1}\right.$ d.w.). Diclofenac was not found in tomato fruits harvested during the first year of the study. However, diclofenac displayed the highest fruit concentration ( $11.63 \mu \mathrm{g} \mathrm{kg}^{-1} \mathrm{~d}$.w.) throughout the study, likely as a result of the prolonged TWW irrigation, followed by sulfamethoxazole (5.26 $\mu \mathrm{g} \mathrm{kg}^{-1}$ d.w.) and trimethoprim $\left(3.40 \mu \mathrm{g} \mathrm{kg}^{-1}\right.$ d.w.).

Wu et al. (2010) studied the uptake of three PhACs (carbamazepine, diphenhydramine, and fluoxetine) and two chemicals from PCPs (triclosan and triclocarban) by soybean (Glycine max (L.) Merr.) plants grown in pots in a greenhouse, where the soil was either amended with biosolids or irrigated with TWW. Results showed that carbamazepine, triclosan, and triclocarban were concentrated in root tissues and translocated into the above ground parts including beans, whereas accumulation and translocation for diphenhydramine and fluoxetine was limited. The uptake of the selected CECs was found to vary with treatment, with biosolids application resulting in higher plant concentrations, probable due to higher loading. However, compounds introduced by irrigation appeared to be more available for uptake and translocation. In another study, Wu et al. (2012) found that carbamazepine, diphenhydramine, and triclocarban were taken up and accumulated in lettuce, radish, tomato, pepper and collard grown in biosolids-treated soils. Root concentration factor (RCF) and shoot concentration factor (SCF) were found highest for carbamazepine followed by triclocarban and diphenhydramine. Carbamazepine concentration in the shoot system of studied plants decreased in the order of pepper $>$ collard $>$ lettuce $>$ tomato $>$ radish, while it was only detected in the fruits of pepper. Diphenhydramine and triclocarban ware only detected in the fruits of tomato and pepper plants, with the concentration in tomatoes being higher compared to that of peppers, while the concentration of these CECs in shoots of all plants did not displayed significant variations.

In a similar experiment, Holling et al. (2012) studied under greenhouse conditions the uptake of carbamazepine, sulfamethoxazole, salbutamol and trimethoprim by Chinese cabbage (Brassica campestris) plants grown in fortified soil, as well as their uptake including triclosan by plants grown in biosolids-amended soil. All PhACs were detected in the roots and the aerial parts of cabbage grown in the fortified soil with median concentrations of $255.4 \mu \mathrm{g} \mathrm{kg}^{-1}$ in the aerial parts and $272.9 \mu \mathrm{g} \mathrm{kg}^{-1}$ in roots for carbamazepine; $222.8 \mu \mathrm{g} \mathrm{kg}^{-1}$ in the aerial parts and $260.3 \mu \mathrm{g} \mathrm{kg}^{-1}$ in roots for sulfamethoxazole; $108.3 \mu \mathrm{g} \mathrm{kg}^{-1}$ in the aerial parts and $140.6 \mu \mathrm{g} \mathrm{kg}^{-1}$ in roots for salbutamol; and $20.6 \mu \mathrm{g}$ $\mathrm{kg}^{-1}$ in the aerial parts and $53.7 \mu \mathrm{g} \mathrm{kg}^{-1}$ in roots for trimethoprim (all in dry weight). Although all studied compounds were present in the biosolids-amended planting soil, only carbamazepine $\left(317.6 \mu \mathrm{g} \mathrm{kg}^{-1}\right.$ in the aerial parts and $416.2 \mu \mathrm{g} \mathrm{kg}^{-1}$ in roots), salbutamol $\left(21.2 \mu \mathrm{g} \mathrm{kg}^{-1}\right.$ in the aerial parts and $187.6 \mu \mathrm{g} \mathrm{kg}^{-1}$ in roots), and triclosan $\left(22.9 \mu \mathrm{gg}^{-1}\right.$ in the aerial parts and $1220.1 \mathrm{\mu g} \mathrm{kg}^{-1}$ in roots) were detected in the aerial parts of the cabbage. Results revealed the differences in the bioavailability and bioaccessibility of PhACs for uptake by plants in fortified and biosolids-amended soils, probably due to the effects of the increased SOM in the biosolids-amended soils.

All the above studies reported the concentration of CECs both in the soil (either irrigated with non-fortified or CECs-fortified TWW or amended with manure or biosolids) and in the edible parts of crop plants studied, thus allowing the estimation of the BCF. The BCFs, reported in these studies for carbamazepine, triclosan and sulfamethoxazole in the various crop plant species are summarized in Table 2, allowing for the identification of the crops with the highest and lowest ability for CECs uptake.

\section{General discussion - ranking of crop plants according to their potential to uptake CECs}

The data presented here indicates that leafy vegetables (i.e. lettuce, spinach, cabbage, celery) constitute the crop plants with the highest ability to uptake and accumulate CECs in their edible tissues. This conclusion is based on the BCF values for carbamazepine, sulfamethoxazole and triclosan in various plant species (as shown in 


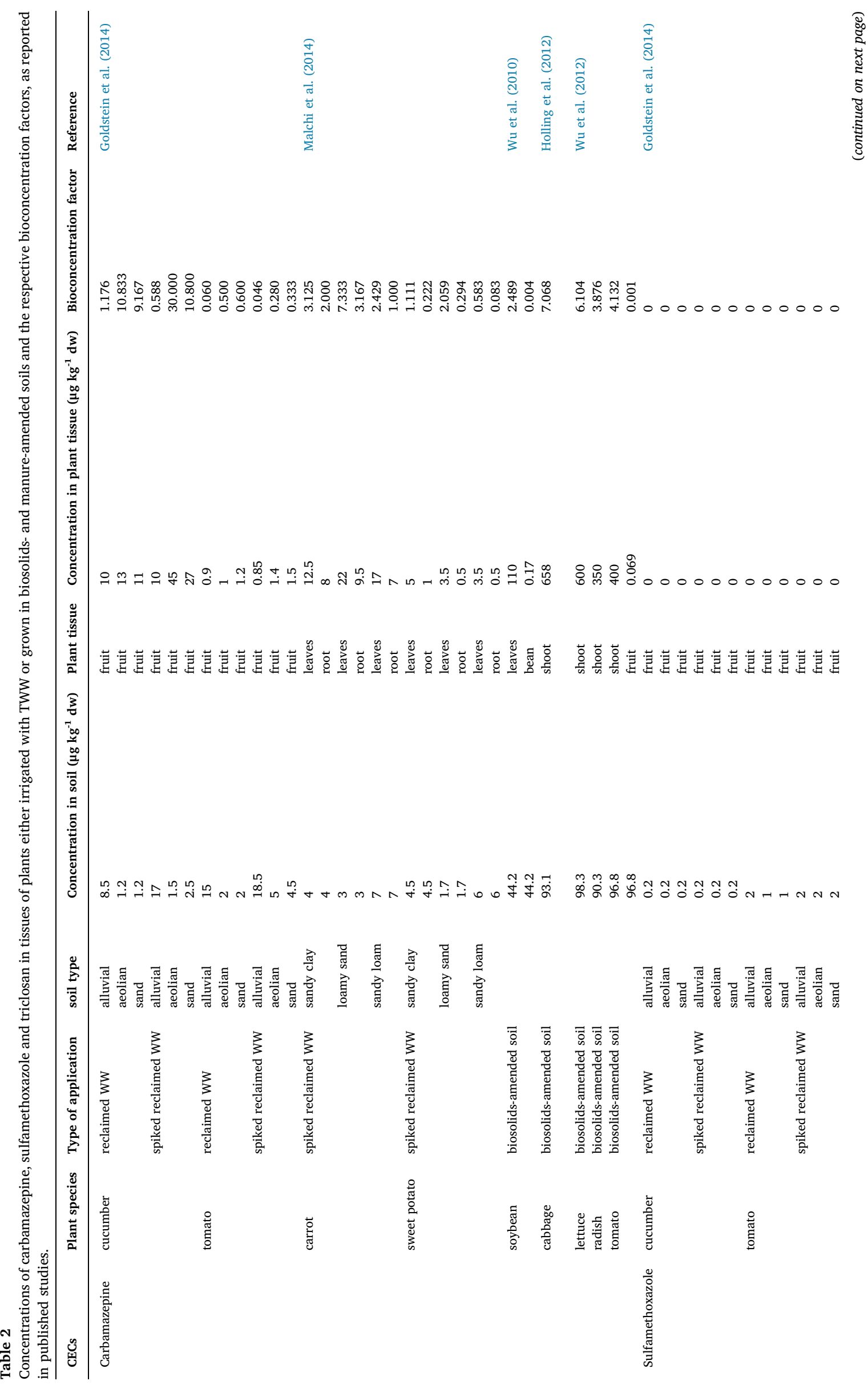




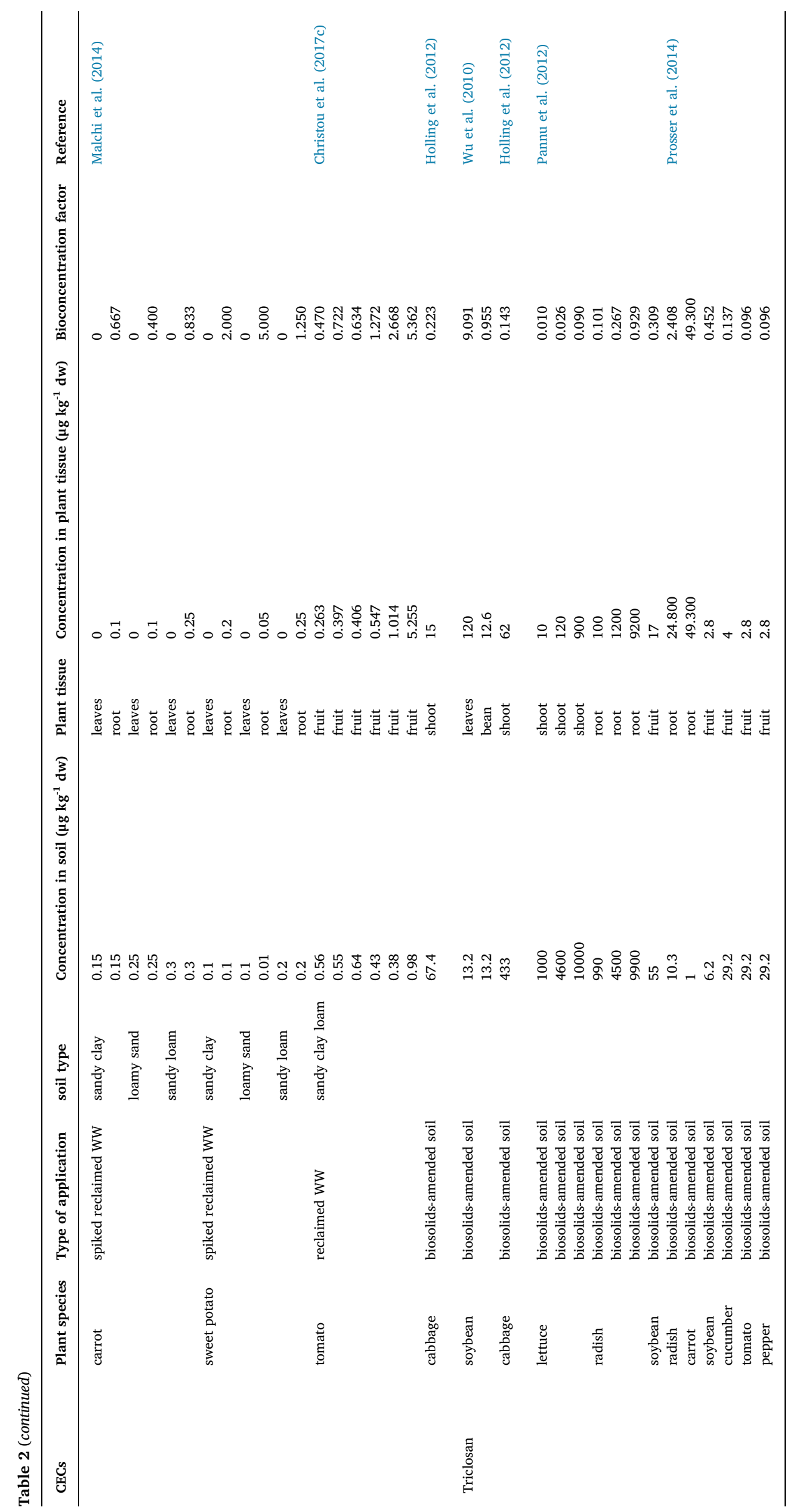




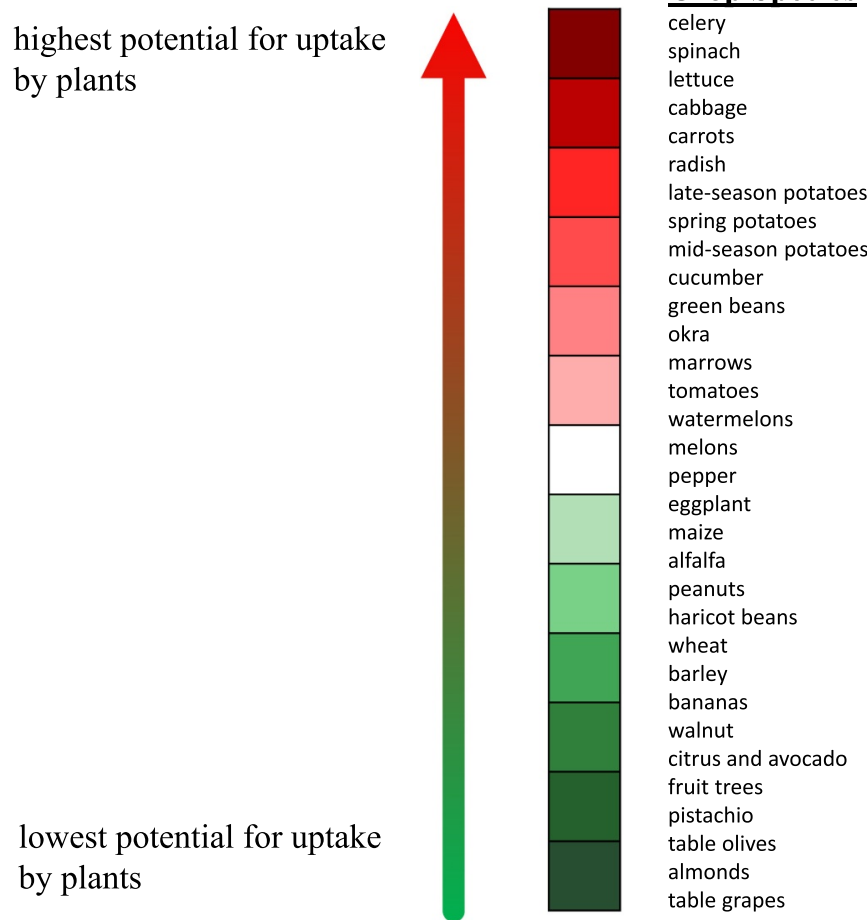

Fig. 2. Heat map showing the potential of the main crop species for CECs uptake. The highest potential for uptake is indicated with dark red; the lowest potential with dark green.

Table 2), as well as on the studies reporting the uptake of other CECs by several plant species and their bioaccumulation in their edible parts (Pannu et al., 2012; Pan et al., 2014; Wu et al., 2014), and also when considering the crop plants' NIR values (Table 1) and irrigation period. Leafy vegetables pose no barriers to the translocation of CECs from their uptake by roots to their edible parts, i.e., the leaves themselves, which show higher concentrations and bioaccumulation factors than other plant parts. Celery is considered as the leafy vegetable crop with the highest ability for CECs uptake, as this crop has longer growing period and higher NIR values $\left(3576 \mathrm{~m}^{3}\right.$ water ha ${ }^{-1}$ year $\left.{ }^{-1}\right)$ compared to other leafy vegetables. Based on reported BCF and NIR values, the ability of other leafy vegetables crops to uptake and accumulate CECs decrease in the order of spinach $>$ cabbage $>$ lettuce (Fig. 2), as the respective NIR values of these crops are 3101,2559 and $2268 \mathrm{~m}^{3}$ water ha ${ }^{-1}$ year $^{-1}$, respectively.

Following leafy vegetables, root vegetables and vegetables forming tubers and bulbs, such as carrot, radish, sweet potato and potatoes, display high ability to uptake and accumulate CECs. Worth noting is that the edible parts of these crops (roots, tubers, bulbs) is in direct contact with the bioavailable fraction of CECs present in soil pore water, enabling CECs to penetrate these tissues, depending on their physico-chemical properties. Based on the data presented in Table 2, as well as on their NIR values, the ability of root vegetables and crops forming bulbs and tubes to uptake CECs decrease in the order of carrot $>$ radish $>$ sweet potatoes $>$ potatoes (Fig. 2). As far as potatoes is concerned, late season potatoes grown during the summer and autumn period (July-November) have higher ability to uptake CECs due to their increased NIR values $\left(4300 \mathrm{~m}^{3}\right.$ water $\mathrm{ha}^{-1}$ year $\left.{ }^{-1}\right)$, followed by spring potatoes $\left(2641 \mathrm{~m}^{3}\right.$ water $\mathrm{ha}^{-1}$ year $\left.{ }^{-1}\right)$ and mid-season potatoes $\left(759 \mathrm{~m}^{3}\right.$ water ha ${ }^{-1}$ year $\left.^{-1}\right)$.

Fruit vegetables (cucumber, tomato, pepper, bean) and cereal crops (corn, rice, wheat) showed a lower ability for CECs uptake compared to leafy and root vegetables (Fig. 2). It is worth noting that cucumber show higher ability for CECs uptake compared to tomato, due to fruit physiology characteristics (Fantke et al., 2011). The ability of fruit vegetable crops to uptake and accumulate CECs based on their reported BCF and NIR values decrease in the order of cucumber $>$ okra $>$ tomatoes $>$ green beans $>$ eggplants $>$ pepper $>$ melons $>$ marrows $>$ watermelons $>$ artichokes $>$ peas (Fig. 2), as all crops are growing during the late spring-summer period and their respective NIR values are 4456, 6289, 6136, 5696, 5448, 5173, 4865, 4772, 4772, 3715 and $1594 \mathrm{~m}^{3}$ water ha ${ }^{-1}$ year $^{-1}$ (Table 1). Fruit vegetables growing under control greenhouse conditions (i.e. cucumber, green beans, tomatoes) have higher potential to uptake and accumulate CECs in their edible parts compared to plants cultivated in open fields. This is likely due to fact that crops grown in greenhouse have longer growing and irrigation period and higher NIR values compared to the same crops cultivated in open fields, as well as to the fact that their water requirements are met solely with irrigation, as no precipitation events occur in protected agriculture.

Fruit trees are assumed to have similar uptake ability for CECs with fruit vegetables; however, more studies are required in order to better elucidate the ability for CECs uptake by fruit trees. No studies have been performed so far for the determination of CECs concentration in fruit trees irrigated with TWW, or grown in biosolids- and manureamended soils.

\section{Concluding remarks - outlook}

Accumulating evidence show that the uptake of CECs by crop plants may be influenced by a variety of factors, both biotic and abiotic. The main biotic factors that may influence the uptake of CECs by crop plants are the plant itself (encompassing the species, the variety and cultivar, the genotype, and the physiological state of the plant), and the soil microorganisms, which constitute the main cause for the biodegradation and biotransformation of CECs within the soil. Climatic conditions and other environmental perturbations (such as temperature, wind speed, UV radiation, salinity, drought, environmental pollution, etc.), the physico-chemical properties of CECs and soil composition constitute the main abiotic factors that influence the potential for CECs uptake by crop plants. The majority of studies with regard to CECs uptake, either conducted in controlled laboratory or greenhouse conditions or under field or simulated conditions, employed mostly (a) vegetables (leafy vegetables such as lettuce and cabbage, fruit vegetables such as tomato and cucumber, and root vegetables such as carrot and radish) and (b) cereals and fodder crops (i.e. maize, wheat, alfalfa). Experimental results revealed that the potential for CECs uptake by crop plants decreased in the order of leafy vegetables $>$ root vegetables $>$ cereals and fodder crops $>$ fruit vegetables.

However, the uptake of CECs by important crop plants, such as fruit trees, is not yet evaluated. Fruit trees, such as citrus, bananas, apple and other fruit bearing trees, have high NIR and evapotranspiration rates, which may render them as plants with moderate to high potential for CECs uptake (similar to that of fruit vegetables). In addition, field studies, where a wider range of plant species are incorporated (fruit trees included), must be performed in order to shed light on the uptake of CECs by crop plants under realistic agricultural conditions. Moreover, the quantification of the examined CECs (including their metabolites) in both the edible parts of the examined plants and in the growing medium (TWW-irrigated or biosolids- or manure-amended soil, substrates, etc.) is of high importance, as it will allow the calculation of the BCF and the better understanding of the potential of crop plants to uptake and accumulate CECs, and consequently the assessment of the risk from the consumption of agricultural products grown in biosolids- or manure-amended soils and/or irrigated with TWW.

\section{Acknowledgements}

The authors would like to acknowledge the COST Action ES1403 NEREUS "New and emerging challenges and opportunities in 
wastewater reuse", supported by COST (European Cooperation in Science and Technology), www.cost.eu.

\section{References}

Ahuja, I., de Vos, R.C., Bones, A.M., Hall, R.D., 2010. Plant molecular stress responses face climate change. Trends Plant Sci. 15 (12), 664-674.

Allen, R.G., Pereira, L.S., Raes, D., Smith, M., 1998. Crop Evapotranspiration - Guidelines for Computing Crop Water Requirements. FAO Irrigation and Drainage Paper 56 FAO, Rome.

Ashbolt, N.J., Amezquita, A., Backhaus, T., Borriello, P., Brandt, K.K., Collignon, P. Coors, A., Finley, R., Gaze, W.H., Heberer, T., Lawrence, J.R., Larsson, D.G.J., McEwen, S.A., Ryan, J.J., Schoenfeld, J., Silley, P., Snape, J.R., Van den Eede, C., Topp, E., 2013. Human Health Risk Assessment (HHRA) for environmental development and transfer of antibiotic resistance. Environ. Health Perspect. 121 (9), 993-1001.

Bixio, D., Thoeye, C., De Koning, J., Joksimovic, D., Savic, D., Wintgens, T., Melin, T., 2006. Wastewater reuse in Europe. Desalination 187 (1-3), 89-101.

Borgman, O., Chefetz, B., 2013. Combined effects of biosolids application and irrigation with reclaimed wastewater on transport of pharmaceutical compounds in arable soils. Water Res. 47 (10), 3431-3443.

Boxall, A.B., Rudd, M.A., Brooks, B.W., Caldwell, D.J., Choi, K., Hickmann, S., Innes, E., Ostapyk, K., Staveley, J.P., Verslycke, T., 2012. Pharmaceuticals and personal care products in the environment: what are the big questions? Environ. Health Perspect. 120 (9), 1221.

Calderón-Preciado, D., Jiménez-Cartagena, C., Matamoros, V., Bayona, J.M., 2011a. Screening of 47 organic microcontaminants in agricultural irrigation waters and their soil loading. Water Res. 45 (1), 221-231.

Calderón-Preciado, D., Matamoros, V., Bayona, J.M., 2011b. Occurrence and potential crop uptake of emerging contaminants and related compounds in an agricultural irrigation network. Sci. Total Environ. 412-413 (0), 14-19.

Calderón-Preciado, D., Matamoros, V., Save, R., Munoz, P., Biel, C., Bayona, J.M., 2013. Uptake of microcontaminants by crops irrigated with reclaimed water and groundwater under real field greenhouse conditions. Environ. Sci. Pollut. Res. Int. 20 (6), 3629-3638.

Christou, A., Antoniou, C., Christodoulou, C., Hapeshi, E., Stavrou, I., Michael, C., FattaKassinos, D., Fotopoulos, V., 2016. Stress-related phenomena and detoxification mechanisms induced by common pharmaceuticals in alfalfa (Medicago sativa L.) plants. Sci. Total Environ. 557-558, 652-664.

Christou, A., Agüiera, A., Bayona, J.M., Cytryn, E., Fotopoulos, V., Lambropoulou, D., Manaia, C.M., Michael, C., Revitt, M., Schröder, P., Fatta-Kassinos, D., 2017a. The potential implications of reclaimed wastewater reuse for irrigation on the agricultural environment: the knowns and unknowns of the fate of antibiotics and antibiotic resistant bacteria and resistance genes - a review. Water Res. 123, 448-467.

Christou, A., Dalias, P., Neocleous, D., 2017b. Spatial and temporal variations in evapotranspiration and net water requirements of typical Mediterranean crops on the island of Cyprus. J. Agric. Sci. 155 (8), 1311-1323.

Christou, A., Karaolia, P., Hapeshi, E., Michael, C., Fatta-Kassinos, D., 2017c. Long-term wastewater irrigation of vegetables in real agricultural systems: concentration of pharmaceuticals in soil, uptake and bioaccumulation in tomato fruits and human health risk assessment. Water Res. 109, 24-34.

Dalkmann, P., Broszat, M., Siebe, C., Willaschek, E., Sakinc, T., Huebner, J., Amelung, W., Grohmann, E., Siemens, J., 2012. Accumulation of Pharmaceuticals, Enterococcus, and Resistance Genes in Soils Irrigated with Wastewater for Zero to 100 Years in Central Mexico. PLoS ONE 7, e45397.

Dodgen, L.K., Ueda, A., Wu, X., Parker, D.R., Gan, J., 2015. Effect of transpiration on plant accumulation and translocation of PPCP/EDCs. Environ. Pollut. 198 (0), 144-153.

Eggen, T., Asp, T.N., Grave, K., Hormazabal, V., 2011. Uptake and translocation of metformin, ciprofloxacin and narasin in forage- and crop plants. Chemosphere 85 (1), 26-33.

Fantke, P., Juraske, R., Antón, A., Friedrich, R., Jolliet, O., 2011. Dynamic multicrop model to characterize impacts of pesticides in food. Environ. Sci. Technol. 45 (20), 8842-8849.

Fatta-Kassinos, D., Kalavrouziotis, I.K., Koukoulakis, P.H., Vasquez, M.I., 2011. The risks associated with wastewater reuse and xenobiotics in the agroecological environment. Sci. Total Environ. 409 (19), 3555-3563.

Franklin, A.M., Williams, C.F., Andrews, D.M., Woodward, E.E., Watson, J.E., 2016. Uptake of three antibiotics and an antiepileptic drug by wheat crops spray irrigated with wastewater treatment plant effluent. J. Environ. Qual. 45 (2), 546-554.

Gao, Y., Zhu, L., 2004. Plant uptake, accumulation and translocation of phenanthrene and pyrene in soils. Chemosphere 55, 1169-1178.

Goldstein, M., Shenker, M., Chefetz, B., 2014. Insights into the uptake processes of wastewater-borne pharmaceuticals by vegetables. Environ. Sci. Technol. 48 (10), 5593-5600.

Gottschall, N., Topp, E., Metcalfe, C., Edwards, M., Payne, M., Kleywegt, S., Russell, P., Lapen, D.R., 2012. Pharmaceutical and personal care products in groundwater, subsurface drainage, soil, and wheat grain, following a high single application of municipal biosolids to a field. Chemosphere 87 (2), 194-203.

Grossberger, A., Hadar, Y., Borch, T., Chefetz, B., 2014. Biodegradability of pharmaceutical compounds in agricultural soils irrigated with treated wastewater. Environ. Pollut. 185, 168-177.

Hepworth, C., Doheny-Adams, T., Hunt, L., Cameron, D.D., Gray, J.E., 2015. Manipulating stomatal density enhances drought tolerance without deleterious effect on nutrient uptake. New Phytol. 208 (2), 336-341.

Herklotz, P.A., Gurung, P., Vanden Heuvel, B., Kinney, C.A., 2010. Uptake of human pharmaceuticals by plants grown under hydroponic conditions. Chemosphere 78 (11), 1416-1421.
Holling, C.S., Bailey, J.L., Vanden Heuvel, B., Kinney, C.A., 2012. Uptake of human pharmaceuticals and personal care products by cabbage (Brassica campestris) from fortified and biosolids-amended soils. J. Environ. Monit. 14 (11), 3029-3036.

Huang, H., Zhang, S., Christie, P., Wang, S., Xie, M., 2009. Behavior of decabromodiphenyl ether (BDE-209) in the soil-plant system: uptake, translocation, and metabolism in plants and dissipation in soil. Environ. Sci. Technol. 44, 663-667.

Hurtado, C., Trapp, S., Bayona, J.M., 2016. Inverse modeling of the biodegradation of emerging organic contaminants in the soil-plant system. Chemosphere 156, 236-244.

Iglesias, A., Garrote, L., 2015. Adaptation strategies for agricultural water management under climate change in Europe. Agric. Water Manag. 155, 113-124.

Juraske, R., Castells, F., Vijay, A., Muñoz, P., Antón, A., 2009. Uptake and persistence of pesticides in plants: measurements and model estimates for imidacloprid after foliar and soil application. J. Hazard. Mater. 165 (1-3), 683-689.

Kinney, C.A., Furlong, E.T., Werner, S.L., Cahill, J.D., 2006. Presence and distribution of wastewater-derived pharmaceuticals in soil irrigated with reclaimed water. Environ. Toxicol. Chem. 25, 317-326.

Kolpin, D.W., Furlong, E.T., Meyer, M.T., Thurman, E.M., Zaugg, S.D., Barber, L.B., Buxton, H.T., 2002. Pharmaceuticals, hormones, and other organic wastewater contaminants in U.S. streams, 1999-2000: a National Reconnaissance. Environ. Sci. Technol. 36 (6), 1202-1211.

Kong, W.D., Zhu, Y.G., Liang, Y.C., Zhang, J., Smith, F.A., Yang, M., 2007. Uptake of oxytetracycline and its phytotoxicity to alfalfa (Medicago sativa L.). Environ. Pollut. 147 (1), 187-193.

Liu, F., Ying, G.-G., Yang, J.-F., Zhou, L.-J., Tao, R., Wang, L., Zhang, L.-J., Peng, P.-A., 2010. Dissipation of sulfamethoxazole, trimethoprim and tylosin in a soil under aerobic and anoxic conditions. Environ. Chem. 7 (4), 370-376.

Luo, Y., Guo, W., Ngo, H.H., Nghiem, L.D., Hai, F.I., Zhang, J., Liang, S., Wang, X.C., 2014. A review on the occurrence of micropollutants in the aquatic environment and their fate and removal during wastewater treatment. Sci. Total Environ. 473-474 (0), 619-641.

Malchi, T., Maor, Y., Tadmor, G., Shenker, M., Chefetz, B., 2014. Irrigation of root vegetables with treated wastewater: evaluating uptake of pharmaceuticals and the associated human health risks. Environ. Sci. Technol. 48 (16), 9325-9333.

Manaia, C.M., Rocha, J., Scaccia, N., Marano, R., Radu, E., Biancullo, F., Cerqueira, F., Fortunato, G., Iakovides, I.C., Zammit, I., Kampouris, I., Vaz-Moreira, I., Nunes, O.C., 2018. Antibiotic resistance in wastewater treatment plants: tackling the black box. Environ. Int 115, 312-324.

March, H., Therond, O., Leenhardt, D., 2012. Water futures: reviewing water-scenario analyses through an original interpretative framework. Ecol. Econ. 82 (0), 126-137.

Marsoni, M., De Mattia, F., Labra, M., Bruno, A., Bracale, M., Vannini, C., 2014. Uptake and effects of a mixture of widely used therapeutic drugs in Eruca sativa L. and Zea mays L. plants. Ecotoxicol. Environ. Saf. 108 (0), 52-57.

Meffe, R., de Bustamante, I., 2014. Emerging organic contaminants in surface water and groundwater: a first overview of the situation in Italy. Sci. Total Environ. 481 (0), 280-295.

Milano, M., Ruelland, D., Fernandez, S., Dezetter, A., Fabre, J., Servat, E., 2012. Facing climatic and anthropogenic changes in the Mediterranean basin: what will be the medium-term impact on water stress? Comptes Rendus Geosci. 344 (9), 432-440.

Miller, E.L., Nason, S.L., Karthikeyan, K.G., Pedersen, J.A., 2016. Root uptake of phar maceuticals and personal care product ingredients. Environ. Sci. Technol. 50 (2), 525-541.

Pan, M., Chu, L.M., 2016. Adsorption and degradation of five selected antibiotics in agricultural soil. Sci. Total Environ. 545-546 (48-56), 48-56.

Pan, M., Wong, C.K.C., Chu, L.M., 2014. Distribution of Antibiotics in WastewaterIrrigated Soils and Their Accumulation in Vegetable Crops in the Pearl River Delta, Southern China. J. Agric. Food Chem. 62 (46), 11062-11069.

Pannu, M.W., Toor, G.S., O'Connor, G.A., Wilson, P.C., 2012. Toxicity and bioaccumulation of biosolids-borne triclosan in food crops. Environ. Toxicol. Chem. 31 (9), 2130-2137.

Park, J.Y., Huwe, B., 2016. Effect of pH and soil structure on transport of sulfonamide antibiotics in agricultural soils. Environ. Pollut. 213, 561-570.

Pedersen, J.A., Yeager, M.A., Suffet, I.H., 2003. Xenobiotic organic compounds in runoff from fields irrigated with treated wastewater. J. Agric. Food Chem. 51 (5), 1360-1372.

Picó, Y., Alvarez-Ruiz, R., Alfarhan, A.H., El-Sheikh, M.A., Alobaid, S.M., Barceló, D., 2019. Uptake and accumulation of emerging contaminants in soil and plant treated with wastewater under real-world environmental conditions in the Al Hayer area (Saudi Arabia). Sci. Total Environ. 652, 562-572.

Piña, B., Bayona, J.M., Christou, A., Fatta-Kassinos, D., Guillon, E., Lambropoulou, D., Michael, C., Polesel, F., Sayen, S., 2018. On the contribution of reclaimed wastewater irrigation to the potential exposure of humans to antibiotics, antibiotic resistant bacteria and antibiotic resistance genes - NEREUS COST Action ES1403 position paper. J. Environ. Chem. Eng.

Prosser, R.S., Sibley, P.K., 2015. Human health risk assessment of pharmaceuticals and personal care products in plant tissue due to biosolids and manure amendments, and wastewater irrigation. Environ. Int. 75 (0), 223-233.

Prosser, R.S., Trapp, S., Sibley, P.K., 2014. Modeling uptake of selected pharmaceuticals and personal care products into food crops from biosolids-amended soil. Environ. Sci. Technol. 48 (19), 11397-11404.

Rand-Weaver, M., Margiotta-Casaluci, L., Patel, A., Panter, G.H., Owen, S.F., Sumpter, J.P., 2013. The read-across hypothesis and environmental risk assessment of pharmaceuticals. Environ. Sci. Technol. 47 (20), 11384-11395.

Riemenschneider, C., Al-Raggad, M., Moeder, M., Seiwert, B., Salameh, E., Reemtsma, T., 2016. Pharmaceuticals, their metabolites, and other polar pollutants in field-grown vegetables irrigated with treated municipal wastewater. J. Agric. Food Chem. 64 (29), 5784-5792.

Shenker, M., Harush, D., Ben-Ari, J., Chefetz, B., 2011. Uptake of carbamazepine by cucumber plants - a case study related to irrigation with reclaimed wastewater. Chemosphere 82 (6), 905-910.

Tanoue, R., Sato, Y., Motoyama, M., Nakagawa, S., Shinohara, R., Nomiyama, K., 2012. 
Plant uptake of pharmaceutical chemicals detected in recycled organic manure and reclaimed wastewater. J. Agric. Food Chem. 60 (41), 10203-10211.

Thiele-Bruhn, S., Seibicke, T., Schulten, H.-R., Leinweber, P., 2004. Sorption of sulfonamide pharmaceutical antibiotics on whole soils and particle-size fractions. J. Environ. Qual. 33 (4), 1331-1342.

Trapp, S., 2000. Modelling uptake into roots and subsequent translocation of neutral and ionisable organic compounds. Pest Manag. Sci. 56 (9), 767-778.

Trapp, S., 2004. Plant uptake and transport models for neutral and ionic chemicals. Environ. Sci. Pollut. Res. 11 (1), 33-39.

Trapp, S., 2015. Calibration of a plant uptake model with plant-and site-specific data for uptake of chlorinated organic compounds into radish. Environ. Sci. Technol. 49 (1), 395-402.

Vasudevan, D., Bruland, G.L., Torrance, B.S., Upchurch, V.G., MacKay, A.A., 2009. pHdependent ciprofloxacin sorption to soils: interaction mechanisms and soil factors influencing sorption. Geoderma 151 (3ß€"4), 68-76.

Wu, C., Spongberg, A.L., Witter, J.D., Fang, M., Czajkowski, K.P., 2010. Uptake of pharmaceutical and personal care products by soybean plants from soils applied with biosolids and irrigated with contaminated water. Environ. Sci. Technol. 44 (16), $6157-6161$.

Wu, C., Spongberg, A.L., Witter, J.D., Sridhar, B.B.M., 2012. Transfer of wastewater associated pharmaceuticals and personal care products to crop plants from biosolids treated soil. Ecotoxicol. Environ. Saf. 85 (0), 104-109.

Wu, Q., Li, Z., Hong, H., Li, R., Jiang, W.-T., 2013. Desorption of ciprofloxacin from clay mineral surfaces. Water Res. 47 (1), 259-268.

Wu, X., Conkle, J.L., Ernst, F., Gan, J., 2014. Treated wastewater irrigation: uptake of pharmaceutical and personal care products by common vegetables under field conditions. Environ. Sci. Technol. 48 (19), 11286-11293.

Wu, X., Dodgen, L.K., Conkle, J.L., Gan, J., 2015. Plant uptake of pharmaceutical and personal care products from recycled water and biosolids: a review. Sci. Tota Environ. 536, 655-666.

Zhang, Y., Shen, Y., 2017. Wastewater Irrigation: Past, Present, and Future. Wiley Interdisciplinary Reviews: Water, pp. e1234.

Zhang, Y., Sallach, J.B., Hodges, L., Snow, D.D., Bartelt-Hunt, S.L., Eskridge, K.M., Li, X., 2016. Effects of soil texture and drought stress on the uptake of antibiotics and the internalization of Salmonella in lettuce following wastewater irrigation. Environ. Pollut. 208, Part B 523-531.

Zhang, Y.-L., Lin, S.-S., Dai, C.-M., Shi, L., Zhou, X.-F., 2014. Sorption-desorption and transport of trimethoprim and sulfonamide antibiotics in agricultural soil: effect of soil type, dissolved organic matter, and pH. Environ. Sci. Pollut. Res. 21 (9), 5827-5835. 